\title{
RESPONSABILIDADE SOCIAL CORPORATIVA NA PRODUÇÃO DE CACAU: ANÁLISE DAS AÇÕES DA INDÚSTRIA DE CHOCOLATE
}

CORPORATE SOCIAL RESPONSIBILITY IN COCOA PRODUCTION: ANALYSIS OF CHOCOLATE INDUSTRY ACTIONS

Eduardo Cesar Silva

Doutorando em Administração (Universidade Federal de Lavras/Brasil).E-mail: educesar_muz@hotmail.com.

Angélica da Silva Azevedo Mestranda em Administração (Universidade Federal de Lavras/Brasil). E-mail: angelica.soad@gmail.com.

\section{Marina de Barros}

Mestranda em Administração (Universidade Federal de Lavras/Brasil).E-mail: marinabarros0@hotmail.com.

\section{Nilmar Diogo dos Reis}

Mestrando em Administração (Universidade Federal de Lavras/Brasil).E-mail: nilmardiogo@yahoo.com.br. 


\section{RESUMO}

O cultivo do cacau é uma importante fonte de renda para milhões de pequenos produtores ao redor mundo, a maioria em países com baixo PIB per capita e problemas de infraestrutura. Além disso, a cacauicultura enfrenta problemas relacionados à volatilidade dos preços, baixa produtividade, condições precárias de trabalho e incidência de pragas e doenças. Nesse cenário, ações socialmente responsáveis realizadas pelas companhias de chocolate podem promover melhorias no desenvolvimento social e econômico das comunidades. Com isso, o objetivo do presente estudo foi identificar as práticas de Responsabilidade Social Corporativa (RSC) empregadas pelas seis maiores fabricantes de chocolate do mundo, mais especificamente, aquelas que afetam diretamente os produtores. A RSC tem como intuito promover relações éticas, responsáveis e solidárias entre as empresas e a sociedade. Os resultados mostram que todas as empresas analisadas investem em programas que beneficiam as comunidades de produtores e possuem estratégias para a aquisição de cacau sustentável. Na cadeia do cacau, tais ações são necessárias por conta das dificuldades enfrentadas pelos produtores.

Palavras-chave: Responsabilidade social corporativa. Certificação. Agricultores. Cacau.

\section{ABSTRACT}

Cocoa cultivation is an important income source for millions of small farmers around the world, most of them in countries with low per capita GDP and infrastructure problems. In addition, cocoa cultivation faces problems related to price volatility, low productivity, poor working conditions and the incidence of pests and diseases. In this context, socially responsible actions undertaken by chocolate companies can generate improvements in the social and economic development of rural communities. The aim of this paper was to identify the Corporate Social Responsibility (CSR) practices employed by the six largest chocolate manufacturers in the world, specifically those that directly affect cocoa farmers. CSR aims to promote ethical, responsible and supportive relationships between companies and society. The results show that all the companies analyzed invest in programs that benefit the communities of producers and have strategies for the acquisition of sustainable cocoa. Such actions are especially necessary in the cocoa chain because of the difficulties faced by producers.

Keywords: Corporate social responsibility. Certification. Farmers. Cocoa. 


\section{INTRODUÇÃO}

O cacau é cultivado em países da África, América, Ásia e Oceania. O continente africano é o maior produtor da amêndoa, tendo fornecido cerca de 66\% de todo o cacau colhido no mundo entre 1994 e 2014. No continente, os maiores produtores são, atualmente, Costa do Marfim, Gana, Nigéria e Camarões (FOOD AND AGRICULTURE ORGANIZATION - FAO, 2016).

Segundo o relatório Sustainable Cocoa Economy, publicado pela International Cocoa Organization (ICCO) a produção de cacau está concentrada em países com um PIB per capita baixo, com pouca infraestrutura e deficiências no setor de comunicações. Nesses países o cultivo é, em sua maior parte, realizado por pequenos produtores e em propriedades com tamanho de um a três hectares. O relatório também enfatiza que o setoré marcado por preços voláteis, produção concentrada em poucos países, baixa produtividade e perdas devido a pragas e doenças (ICCO, 2007).

Conforme a KPMG (2012), em Costa do Marfim e Gana, os dois maiores produtores mundiais, a atividade recebe um baixo nível de investimentos devido à volatilidade dos preços e as altas taxas impostas aos agricultores. Esse baixo nível de investimentos compromete a aquisição de insumos, a formação adequada dos agricultores e a implementação de boas práticas agrícolas; o que afeta diretamente a qualidade das amêndoas.

Além das preocupações econômicas com a cadeia do cacau, existem também as preocupações sociais relacionadas ao trabalho infantil e escravo (KPMG, 2012). Segundo relatório da Universidade Tulane (2015), na safra 2013/2014, cerca 2,1 milhões de crianças foram submetidas ao trabalho infantil na produção de cacau em Gana e Costa do Marfim. Dessas, 2 milhões exerceram atividades consideradas perigosas.

Os problemas existentes na cadeia do cacau relacionados ao meio ambiente e às condições de trabalho afetam diretamente o mercado de chocolate. Segundo a ICCO (2007), os consumidores exigem, cada vez mais, práticas sustentáveis para a produção de cacau e chocolate. Eles anseiam consumir produtos que proporcionem uma vida decente aos produtores, que não prejudiquem o meio ambiente e sejam produzidos de uma forma socialmente justa.

Para atender as demandas tanto dos consumidores, que exigem produtos fabricados dentro de normas socialmente responsáveis, quanto dos produtores e comunidades locais, que anseiam por melhorias nas condições de trabalho e de vida, além da preservação do meio ambiente, as empresas recorrem aos preceitos da Responsabilidade Social Corporativa (RSC), que promovem uma interação ética e solidária entre as empresas e o meio onde ela atua. 
Na produção de cacau, especificamente, espera-se que a atividade seja capaz de proporcionar melhorias para os agricultores, com a garantia de níveis aceitáveis de subsistência; que a biodiversidade nas áreas de produção seja preservada e práticas adequadas de cultivo sejam adotadas; e que as indústrias assumam compromissos com as questões sociais que afetam os produtores e auxiliem na erradicação do trabalho infantil nas fazendas (ICCO, 2007).

Diante do quadro de precariedade na cadeia produtiva do chocolate e as suas implicações diretas no produto e consumidor final, as empresas do setor passaram a estabelecer programas e metas para que as práticas socialmente responsáveis estejam presentes na cadeia de suprimentos, de forma que o cacau seja produzido de maneira sustentável, sejam realizados investimentos para a capacitação dos produtores e para o desenvolvimento das comunidades rurais.

O objetivo deste trabalho é identificar as práticas de RSC empregadas pelas seis maiores fabricantes de chocolate do mundo, sendo elas Ferrero, Mars, Meiji Company, Mondelez International, Nestlé e The Hershey Company. Especificamente, foram analisadas as ações direcionadas aos produtores de cacau e suas comunidades, bem como as aquisições de cacau certificado efetuadas por cada companhia.

Para atender o objetivo proposto, foi realizada uma pesquisa qualitativa, exploratória, com o emprego da pesquisa documental como metodologia. Os relatórios de responsabilidade social corporativa das empresas selecionadas foram analisados em busca de informações acerca das ações de RSC desenvolvidas por elas.

O trabalho está estruturado em cinco seções, além desta introdução. Na seção seguinte, é apresentado o arcabouço teórico que orienta esta pesquisa, nela é realizada uma discussão acerca do surgimento e evolução do conceito de RSC e a atual relação existente entre as práticas socialmente responsáveis adotadas pelas empresas e sua cadeia de suprimentos. Em seguida, é apresentada a metodologia utilizada. Posteriormente, são apresentados os resultados da pesquisa, seguidos pela análise. E por último, são expostas as considerações finais do estudo.

\section{FUNDAMENTAÇÃO TEÓRICA}

Esta seção apresenta os principais conceitos teóricos que orientaram a condução do trabalho. Eles são discutidos em duas subseções: responsabilidade social corporativa e responsabilidade social corporativa nas cadeias de suprimentos. 


\subsection{RESPONSABILIDADE SOCIAL CORPORATIVA}

Atualmente, as discussões sobre as responsabilidades sociais das empresas estão presentes de forma ampla nos ambientes corporativos, na sociedade civil e na academia. Entretanto, apesar de constituir um tema contemporâneo, sua origem é remetida a debates antigos (KREITLON, 2004). Existem evidências que a preocupação das empresas com a sociedade possui raízes históricas que remontam a séculos (CARROLL, 1999), no entanto, somente começou a ser descrita formalmente a partir da década de 1950 (CARROLL, 1999; MADRAKHIMOVA, 2013).

De acordo com Madrakhimova (2013), se observa neste período o crescimento do interesse do meio científico pelos problemas existentes entre as empresas e a sociedade. Os trabalhos desenvolvidos nesta época apontam conceitos que podem, atualmente, serem associados ao termo RSC.

Segundo a Comissão das Comunidades Europeias (2001), os principais fatores que motivaram a discussão e a evolução dos conceitos de RSC estão relacionados às preocupações da sociedade em relação ao novo cenário globalizado e de grandes mudanças na indústria, a influência dos critérios sociais no processo de tomada de decisões, as crescentes preocupações com os possíveis danos causados ao meio ambiente pelas atividades econômicas e a maior transparência das atividades empresariais proporcionada pelo desenvolvimento dos meios de comunicação.

O livro Social Responsibilities of the Businessman, publicado em 1953 e de autoria de Howard R. Bowen, é apontado como o precursor da teoria de RSC, visto que nele o autor questiona o papel das empresas na sociedade, ressaltando que as ações das organizações interferem na vida dos cidadãos em vários aspectos (CARROLL, 1999; WINDSOR, 2001). Em seu trabalho, Bowen sugere que os empresários tinham a obrigação de tomar decisões e executar ações que fossem consideradas como desejáveis pela sociedade (CARROLL, 2015).

Nas décadas seguintes, as discussões sobre RSC se intensificaram. Os debates acerca do tema possuíam como ideia central a ampliação das preocupações das empresas, que deveriam deixar de se limitar apenas pela maximização de lucro e começar a abranger pensamentos relacionados a uma melhor utilização dos recursos da sociedade para fins sociais. A RSC também foi incorporada ao debate público sobre problemas sociais relacionados à pobreza, diversidade, desenvolvimento, distribuição de renda, poluição, entre outros. Isto promoveu um maior envolvimento das organizações com movimentos ambientais, o surgimento de preocupações com a segurança do trabalho e regulamentações governamentais (BERTONCELLO; CHANG JÚNIOR, 2007). 
Apesar da crescente discussão sobre o relacionamento entre organizações e sociedade, o campo ainda não havia desenvolvido uma definição clara sobre RSC (LEE, 2008). O primeiro a atribuir um significado mais amplo para a responsabilidade social das empresas foi Carroll, a partir da proposta de um modelo conceitual de desempenho social corporativo, publicado em 1979 (BERTONCELLO; CHANG JÚNIOR, 2007; LEE, 2008).

Até aquele momento, a RSC havia recebido uma série de definições e conceitualizações. No entanto, todos esses conceitos poderiam ser agrupados em categorias distintas, que refletiam as responsabilidades que as organizações deveriam assumir perante a sociedade. A partir dessa classificação, Carroll criou um modelo conceitual que, de acordo com ele, reflete os principais aspectos presentes no desempenho social corporativo (CARROLL, 1979). Com base nessas categorias, foi possível perceber que as organizações não possuem apenas obrigações econômicas e legais, mas também éticas e discricionárias. Deste modo, para que o conceito de RSC seja aceito como legítimo, deve considerar essas quatro responsabilidades (CARROLL, 1991).

Segundo Carroll (1979), a responsabilidade econômica abrange a ideia de que as organizações possuem a responsabilidade de produzir bens e serviços que atendam a demanda da sociedade, além de vendêlos com margem de lucro. Carroll (1991) complementa que as empresas devem manter uma forte posição competitiva, um alto nível de eficiência operacional e ser consistentemente rentável.

De acordo com a responsabilidade legal, as empresas devem exercer suas atividades econômicas de acordo com os requisitos legais (CARROLL, 1979). Com o atendimento dos regulamentos dos governos federal, estadual e local, e fornecendo produtos e serviços que estejam de acordo com as exigências legais mínimas (CARROLL, 1991).

Aresponsabilidadeética presumequenemtodososcomportamentoseatividadessão regidos porleis, entretanto, espera-se que as empresas ajam além dos requerimentos legais (CARROLL, 1979). As responsabilidades éticas incorporam os padrões e normas que refletem o que os consumidores, funcionários, acionistas e a comunidade consideram como justo e de acordo com os princípios morais estabelecidos (CARROLL, 1991).

Já a responsabilidade discricionária está relacionada a tarefas que não são diretamente ligadas ao negócio e também não são exigidas por lei, mas que são assumidas e executadas de forma voluntária pelas organizações, como programas filantrópicos, por exemplo (CARROLL, 1979). Segundo esta responsabilidade, espera-se que as empresas e seus colaboradores desempenhem atividades voltadas à caridade, prestem assistência às organizações educacionais e auxiliem projetos voltados para a melhoria da qualidade de vida da comunidade em que está inserida (CARROLL, 1991). 
Embora a definição de Carroll seja amplamente empregada e reconhecida, ainda não há um consenso sobre a definição correta de RSC (BARON, 2001; DAHLSRUD, 2008). O crescimento deste campo de estudo proporcionou uma proliferação de abordagens, teorias e terminologias utilizadas para descrever os fenômenos relacionados à responsabilidade corporativa e sociedade (GARRIGA; MELÉ, 2004).

Em muitos casos, o conceito de RSC é relacionado à responsabilidade legal, em outros é associado a comportamentos socialmente responsáveis. Há ainda momentos em que o termo é utilizado para entender os relacionamentos entre clientes e fornecedores, qualidade, satisfação do cliente, desenvolvimento de comunidades, conservação ambiental, participação dos funcionários nas decisões e resultados, investimentos em segurança do trabalho, desenvolvimento profissional, respeito aos direitos dos cidadãos, além da noção de não aceitar nenhum tipo de discriminação (BERTONCELLO; CHANG JÚNIOR, 2007).

De acordo com o Instituto Ethos (CUSTODIO; MOYA, 2013), a RSC consiste em um posicionamento de gestão ético, transparente e solidário da empresa em relação a todos os públicos com os quais ela se relaciona, bem como o estabelecimento de metas empresariais que estejam de acordo com o desenvolvimento sustentável da sociedade, de forma a preservar os recursos para as próximas gerações, com respeito pela diversidade e a promoção da redução das desigualdades sociais.

Já a Associação Brasileira de Normas Técnicas (ABNT), por meio da Norma Nacional ABNT NBR 16001, caracteriza a RSC com base nos impactos gerados pelas organizações na sociedade e no meio ambiente. De acordo com a norma, as empresas devem adotar comportamentos éticos e transparentes que contribuam para o desenvolvimento sustentável, devem estar atentas às expectativas de todas as partes interessadas e agir em conformidade com as legislações vigentes. Estes requisitos devem ser integrados em toda a organização, de forma que estejam presentes em todas suas relações (ABNT, 2017).

Para a World Business Council for Sustainable Development (WBCSD), a RSC consiste em um comportamento ético da empresa com a sociedade. Diz respeito a uma gestão responsável que não atenda somente os interesses dos acionistas, e sim de todas as partes interessadas. Está associado aos direitos humanos, direitos dos funcionários, proteção do meio ambiente, envolvimento da comunidade, relacionamento com fornecedores e direito dos stakeholders (WBCSD, 1999).

A Comissão das Comunidades Europeias (2001) divide a RSC em duas dimensões, interna e externa. Na dimensão interna as práticas de responsabilidade social são direcionadas, principalmente, aos funcionários, com preocupações voltadas para o investimento em capital humano, saúde e segurança dos trabalhadores. 
Também está orientada para práticas ambientalmente responsáveis, a partir de uma gestão eficiente dos recursos naturais.

Já a dimensão externa está voltada para a comunidade local, com o envolvimento das demais partes interessadas, como parceiros comerciais, fornecedores, clientes, autoridades públicas e ONGs. Nesta dimensão, busca-se uma melhor integração entre empresa e comunidade, com a promoção da questão ambiental, a seleção de pessoas socialmente excluídas, cuidado à infância, parcerias com a população local, o desenvolvimento de ações culturais e doações para a caridade. Ainda nesta dimensão, espera-se que as empresas ajam de forma ética com todos seus parceiros, respeitem os direitos humanos, obedeçam às legislações estabelecidas e contribuam com o desenvolvimento sustentável do planeta (COMISSÃO DAS COMUNIDADES EUROPEIAS, 2001).

Segundo Kreitlon (2004), apesar das variações das definições de RSC conforme o contexto histórico e social, existe um consenso para que as empresas sejam denominadas como socialmente responsáveis. Segundo a autora, para uma organização receber este rótulo deve, pelo menos, reconhecer os impactos causados por suas atividades na sociedade, gerenciar os impactos econômicos, sociais e ambientais provenientes de suas atividades, aos níveis local e global; e realizar estes propósitos por meio do diálogo constante com as partes interessadas. Muitas vezes, este relacionamento com as demais partes é realizado por meio de parcerias com outros grupos e organizações.

Ashley, Coutinho e Tomei (2000) ressaltam que o conceito de RSC tem tomado um caráter interdisciplinar, multidimensional e sistêmico, com foco nas relações entre os stakeholders ligados direta ou indiretamente ao negócio. Nesse sentido, conforme Aligleri, Aligleri e Câmara (2002), a RSC deixa de ser relacionada apenas ao lado filantrópico, com ações direcionadas à comunidade e assume uma visão de redes de relacionamento, que prevê padrões de conduta para todas as atividades inerentes ao negócio da empresa. Assim, a obrigação de cumprimentos socialmente responsáveis deixa de ser centralizada na fabricante de um determinado produto e se estende para toda a cadeia produtiva da qual a organização faz parte.

\subsection{RESPONSABILIDADE SOCIAL CORPORATIVA NAS CADEIAS DE SUPRIMENTOS}

De acordo com Aligleri, Aligleri e Câmara (2002), a nova compreensão acerca da RSC ultrapassa as fronteiras das empresas e atinge toda a cadeia de suprimentos. Deste modo, as ações internas deixam de ser suficientes para o atendimento de um comportamento socialmente responsável. Surge, então, a necessidade das boas 
práticas se estenderem aos demais elos da cadeia, sob o risco de penalidades caso algum membro não cumpra devidamente com as obrigações sociais.

Para que as partes interessadas sejam atendidas, de acordo com os preceitos da RSC, as empresas determinam códigos de conduta que estabelecem diretrizes e padrões para a melhoria do desempenho social e ambiental. Tais códigos não são limitados apenas à organização, sendo aplicados também em toda a cadeia (PEDERSEN; ANDERSEN, 2006; POHL, 2006).

O sucesso das práticas de RSC de uma empresa é determinado pelas ações de todas as partes da cadeia de suprimentos. As falhas no gerenciamento e controle dos impactos sociais e ambientais da cadeia podem prejudicar a reputação da empresa que estabeleceu os códigos de conduta (PEDERSEN; ANDERSEN, 2006).

Como as empresas são responsáveis pelas condições em que seus produtos são fabricados (PEDERSEN; ANDERSEN, 2006), um ponto fraco na cadeia pode comprometer a imagem do produto final, portanto, elas devem se atentar para as práticas estabelecidas desde os métodos de extração da matéria-prima até os métodos de venda dos distribuidores (ALIGLERI; ALIGLERI; CÂMARA, 2002).

Neergaard e Pedersen (2005), com base na WBCSD (2003), determinaram os principais problemas existentes na cadeia de suprimentos. No nível dos fornecedores, os autores identificaram problemas relacionados ao trabalho infantil, discriminação, longas jornadas de trabalho, abuso dos direitos dos trabalhadores e poluição. No nível da firma, os problemas são relacionados à corrupção, condições perigosas de trabalho e desigualdades sociais na comunidade local. Já no nível dos distribuidores, os problemas identificados foram subornos, competição desleal e investimentos antiéticos.

As cadeias de suprimentos também estão sujeitas a pressões ambientais e sociais, o que influencia no desempenho de seus parceiros (SEURING et al., 2008). Atualmente, as cadeias produtivas agroindustriais são confrontadas por questões sociais e ambientais, como a utilização de defensivos agrícolas, o uso de alimentos geneticamente modificados, a utilização excessiva de recursos naturais como a água e o solo, o desmatamento, a utilização de mão de obra infantil, condições precárias de trabalho, entre outras (DIETZ; AUFFENBERG, 2014).

Em relação à indústria alimentícia, em específico, as questões de RSC na cadeia de suprimentos abrangem elementos como bem-estar, comunidade, ambiente, comércio justo, trabalho, saúde e segurança (MALONI; BROWN, 2006). 
Diante de tantos problemas, a sociedade percebeu que as cadeias de suprimentos também precisam de monitoramento (SEURING et al., 2008). Entretanto, as empresas continuam sendo o principal alvo dos consumidores diante de cadeias de suprimentos deficientes nos requisitos de RSC (MALONI; BROWN, 2006).

De acordo com as questões levantadas acima acerca das cadeias de suprimentos, especialmente as que compõem o setor de alimentos, torna-se necessário um estreito acompanhamento para garantir que os requisitos sociais e ambientais sejam respeitados.

Tal acompanhamento, segundo Dietz e Auffenberg (2014), não é devidamente realizado pelo Estado, que exerce uma baixa regulação das atividades justamente por não se mostrar preparado para acompanhar o novo contexto da produção de alimentícia. Conforme Raynolds, Murray e Heller (2007), este déficit nas regulações estatais, aliada ao desenvolvimento da globalização nas últimas décadas, influenciaram o surgimento de iniciativas voluntárias, privadas, com certificações e normas fundamentadas nos critérios sociais e ambientais, como forma de suprir as supervisões nas cadeias de suprimentos.

As regras e normas de condutas privadas são, em muitos casos, representadas em certificações ou selos que possuem a função de discutir, propor regras e instrumentos que atestem o cumprimento dos padrões estipulados. Geralmente, abordam atributos como: características dos produtos orgânicos, comércio justo, direitos humanos, direitos trabalhistas, entre outros (RODRIGUES, 2013).

De acordo com Donadelli (2011), existem três tipos de processos para a verificação e monitoramento das condutas e padrões estipulados. As certificações de primeira parte, que englobam critérios e verificações realizadas pela própria empresa; as certificações de segunda parte, que possuem o envolvimento de associações empresariais responsáveis pela definição e auditoria dos critérios; e as certificações de terceira parte, realizadas por organizações que não estão vinculadas às empresas ou aos produtores, como ONGs.

As certificações de terceira parte são consideradas as mais transparentes devido à independência da organização certificadora, que estabelece os critérios a serem seguidos e mecanismos de auditoria mais confiáveis (RAYNOLDS; MURRAY; HELLER, 2007). Nas certificações de primeira e segunda parte, interesses particulares podem prevalecer sobre a transparência da iniciativa. Na cadeia produtiva do cacau, as principais certificações de terceira parte, atualmente, são Fairtrade, Rainforest Alliance e Utz Certified. Além dessas, nos últimos anos surgiram várias inciativas de primeira e segunda parte promovidas pelas multinacionais do setor de chocolate.

Os principais objetivos das certificações são a promoção de um comércio justo entre compradores e fornecedores, o desenvolvimento social, econômico e ambiental das comunidades; melhorias nas condições 
de produção e não utilização de trabalho infantil e escravo (FAIR TRADE LABELLING ORGANIZATIONS, 2017); a conservação da biodiversidade e dos recursos naturais; melhoria nos padrões de bem-estar das comunidades; o planejamento eficaz da gestão agrícola (RAINFOREST, 2016); criação de melhores oportunidades para os agricultores e suas famílias; adoção de boas práticas agrícolas e condições dignas de trabalho (UTZ CERTIFIED, 2017).

\section{METODOLOGIA}

A amostra de empresas foi definida a partir da lista dos 100 maiores fabricantes de chocolates e doces do mundo, compilada por Scully (2014). Foram selecionadas as seis maiores: Ferrero, Mars, Meiji Company, Mondelez International, Nestlé e The Hershey Company.

Os dados e informações foram obtidos a partir dos relatórios de responsabilidade social corporativa de cada empresa. Os relatórios consultados eram referentes ao ano fiscal encerrado em 31 de agosto de 2014 (FERRERO, 2015), 31 de dezembro de 2014 (MARS, 2015; NESTLÉ, 2015; MONDELEZ INTERNATIONAL, 2015; THE HERSHEY COMPANY, 2015) e 31 de março de 2015 (MEIJI COMPANY, 2015). Para a obtenção de informações complementares, foram consultados os web sites institucionais e documentos oficiais de algumas companhias (NESTLÉ, 2016a; NESTLÉ, 2016b; MARS, 2014; MEIJI HOLDINGS, 2016).

Este material foi analisado em busca de informações sobre as ações de RSC das companhias que são direcionadas aos produtores de cacau e suas comunidades. Também foram compilados dados sobre as compras de cacau certificado efetuadas por elas.

O presente estudo caracteriza-se como uma pesquisa qualitativa do tipo exploratória, que busca ampliar o conhecimento sobre um assunto específico (GIL, 2007). O procedimento de análise utilizado foi a pesquisa documental, que utiliza documentos "não acadêmicos", como relatórios corporativos, notícias e web sites (GIL, 2002; OLIVEIRA, 2007).

\section{RESULTADOS}

Esta seção apresenta as principais informações sobre aquisição de cacau sustentável e ações que beneficiam os produtores, obtidas a partir da análise de fontes institucionais. Os resultados são apresentados individualmente para cada empresa. 


\subsection{MARS}

a. Aquisição de cacau certificado

De todo o cacau adquirido pela Mars no ano fiscal de 2014, 36\% foi certificado. A empresa tem como meta a compra de 100\% de cacau certificado até 2020. Além disso, o diretor responsável pela sustentabilidade da Mars também é o diretor da World Cocoa Foundation (Fundação Mundial do Cacau), que representa 80\% do mercado global de cacau e trabalha pela sustentabilidade da cacauicultura.

\section{b. Apoio aos produtores}

Em relação ao apoio oferecido aos produtores, a empresa possui o programa Vision for Change, responsável por 16 Centros de Desenvolvimento do Cacau e 52 Cocoa Village Centers na Costa do Marfim. Nesses locais, os agricultores recebem treinamento para se tornarem mais eficientes. O programa também aborda questões de gênero na Costa do Marfim, oferecendo apoio para as mulheres produtoras de forma que elas consigam gerar maiores receitas para suas famílias. No Brasil foi criado o Centro Mars para Ciência do Cacau, localizado na Bahia, onde são desenvolvidos e aprimorados estudos relacionados ao cacau que beneficiarão os produtores.

\subsection{MONDELEZ}

\section{a. Aquisição de cacau certificado}

Segundo o relatório de sustentabilidade da empresa, 12\% do cacau adquirido no ano fiscal de 2014 foi proveniente de fontes sustentáveis. A companhia também afirma que é a maior compradora de cacau com certificação Fairtrade do mundo e participa da World Cocoa Foundation. A Mondelez pretende obter 100\% do seu cacau de fontes sustentáveis, mas não estabeleceu um prazo para isto.

\section{b. Apoio aos produtores}

A Mondelez é responsável pelo Cocoa Life, um projeto com o objetivo de beneficiar 200 mil agricultores e que dispõe de orçamento de US\$ 400 milhões até 2020. A iniciativa foi lançada em 2012 e é realizada no Brasil, Costa do Marfim, Gana, Indonésia, Índia e República Dominicana. O projeto oferece informação e treinamento para os produtores, educação para os jovens das comunidades atendidas e promove uma agricultura ambientalmente correta. Em 2014, 38 mil produtores de 500 comunidades faziam parte do Cocoa Life. 


\subsection{NESTLÉ}

a. Aquisição de cacau certificado

As aquisições de cacau certificado da companhia são feitas por meio do Nestlé Cocoa Plan, que é um programa de certificação da própria Nestlé. Em 2014, foram obtidas 91,8 mil toneladas de cacau produzido dentro das normas do programa, e a meta para 2018 é de 175 mil toneladas. Não foi informado um prazo para obtenção de $100 \%$ do cacau de fontes sustentáveis.

\section{b. Apoio aos produtores}

O Nestlé Cocoa Plan é um programa que busca incrementar a renda dos agricultores, garantir cacau de alta qualidade para a companhia e reduzir problemas como trabalho infantil, desigualdade de gênero e condições sociais precárias. Entre as ações realizadas pelo programa estão o treinamento dos produtores, distribuição de mudas mais resistentes e melhoria do acesso à educação das crianças. Em 2014, mais de 45 mil produtores receberam treinamento e 17 escolas foram reformadas ou construídas.

A Nestlé também atua para que as cooperativas que fornecem o cacau não utilizem trabalho infantil. A meta para 2016 é que 100\% das cooperativas disponham de um programa de monitoramento para identificar uso de crianças no trabalho.

\subsection{MEIJI}

a. Aquisição de cacau certificado

A Meiji não divulga a quantidade de cacau certificado que compra, mas informa que utiliza a certificação Rainforest Alliance em parte das suas aquisições. Um executivo da empresa afirma que ela tem o hábito de visitar as áreas de produção e verificá-las. As áreas produtivas de Gana, por exemplo, são visitadas pela empresa há mais de dez anos.

\section{b. Apoio aos produtores}

A companhia oferece treinamento para os produtores, educação para crianças em comunidades rurais e paga um prêmio pelo cacau obtido. A empresa também cava poços nas comunidades e faz doação de móveis para escolas nas regiões produtoras. Números referentes a essas ações não são divulgados. 


\subsection{FERRERO}

a. Aquisição de Cacau Certificado

No ano fiscal 2013/2014 foram adquiridas 120 mil toneladas de cacau certificado, o que equivale a 40\% do total. A meta para o final de 2018 é elevar este percentual para 75\%; depois, para 100\% até o final de 2020. A empresa compra cacau com as certificações UTZ Certified, Rainforest Alliance e Fairtrade.

\section{b. Apoio aos produtores}

A Ferrero possui um programa para a rastreabilidade do cacau, o que permite identificar de qual propriedade veio cada lote do produto e registrar informações socioeconômicas dos produtores. Segundo a empresa, esses dados ajudam na definição de propostas que atendam aos interesses dos agricultores e das comunidades. Outra iniciativa é a criação de viveiros para produção de mudas nas comunidades. Com isso, os agricultores gastam menos com transporte.

A companhia também desenvolve um projeto para redução do trabalho infantil e aumento da renda de 8,8 mil famílias em Gana. Juntas, elas possuem cerca de 26,4 mil crianças. O "Programa para Eliminação das Piores Formas de Trabalho Infantil no Cacau”, como é chamado, é realizado em parceria com a organização Source Trust e com uma iniciativa do governo ganês.

\subsection{HERSHEY}

a. Aquisição de Cacau Certificado

Em 2014, 30\% do cacau adquirido pela Hershey foi certificado, e a meta para 2020 é chegar aos 100\%. A empresa compra cacau com os selos Fairtrade, UTZ Certified e Rainforest Alliance.

\section{b. Apoio aos produtores}

No seu relatório, a companhia reconhece que as condições nos países africanos são precárias e abrem margem para abusos, como o trabalho infantil e o trabalho forçado. A empresa se posiciona contra essas práticas e não compra cacau de fornecedores que utilizem elas.

Em 2012, a empresa iniciou o programa Learn to Grow, desenvolvido em parceria com a organização Source Trust, do Reino Unido, que oferece treinamento aos agricultores para que eles possam obter a certificação UTZ. O programa começou em Gana e foi expandido para a Nigéria, em 2013, e Costa do Marfim, em 2014. Por meio desta iniciativa, a empresa apoia projetos de água em Gana e pretende distribuir um milhão de mudas de cacaueiro, resistentes à seca e doenças, aos produtores do oeste africano até 2017. Além disso, as metas 
do programa incluem aumentar a produtividade e a renda dos participantes. Até 2019, espera-se que sejam beneficiados 23 mil produtores ganeses, 19 mil marfinenses e 20 mil nigerianos.

Outro projeto relevante é o Cocoalink, em que especialistas enviam informações técnicas para os produtores por meio de telefones celulares. A iniciativa é desenvolvida em parceria com outras empresas e organizações.

\section{ANÁLISE DOS RESULTADOS}

As informações coletadas mostram que todas as empresas analisadas compram cacau sustentável e possuem programas que auxiliam os produtores, principalmente na África. Com relação aos programas de apoio, a maioria das ações envolve treinamento para o aumento da produtividade e adequação às normas de sustentabilidade, distribuição de plantas mais produtivas e resistentes, construção e reforma de escolas, e a identificação e redução dos casos de trabalho infantil. A grande maioria dos programas é desenvolvida em Gana e Costa do Marfim, os dois maiores produtores de cacau do mundo.

Embora o continente africano concentre uma grande proporção da produção global, ele também é uma região com graves problemas econômicos e institucionais. Além de ajudar os produtores, as inciativas de sustentabilidade contribuem para garantir o suprimento de cacau das empresas.

Os principais dados sobre a compra de cacau certificado são apresentados na tabela 1. As aquisições das empresas Ferrero, Hershey e Mars estavam em um patamar semelhante em 2014. Todas elas possuem como meta para 2020 a aquisição de 100\% do cacau proveniente de certificações sustentáveis. A Mondelez, por sua vez, apresentou um volume de compra inferior e não definiu uma data para alcançar os 100\% de cacau certificado, embora seu relatório afirme que o objetivo será alcançado em algum momento do futuro. A Nestlé informa o volume adquirido, mas sem indicação do percentual que ele representa. A companhia também não informou quando pretende alcançar os 100\% de certificação. A Meiji foi a única organização que não forneceu números ou metas e, também, foi a que disponibilizou a menor quantidade de informações relativas às suas ações de sustentabilidade na cadeia do cacau.

Os dados obtidos não oferecem um quadro detalhado das mudanças decorrentes dos programas citados na seção anterior. Ou seja, as companhias informam as ações que são realizadas nos países produtores e, às vezes, até o número de agricultores beneficiados, mas não apresentam informações completas sobre o aumento da produtividade das lavouras ou melhoria na renda dos participantes. A Tabela 1 apresenta os dados sobre aquisição de cacau sustentável e certificado. 
Tabela 1 - Dados sobre a compra de cacau sustentável pelas empresas analisadas em 2014

\begin{tabular}{l|l|l|l}
\hline Empresa & $\begin{array}{l}\text { Compras de cacau } \\
\text { sustentável em 2014 }\end{array}$ & Meta para 2020 & Certificações \\
\hline Ferrero & $40 \%$ & $\mathbf{1 0 0 \%}$ & UTZ Certified, Rainforest Alliance e Fairtrade \\
Hershey & $\mathbf{3 0 \%}$ & $\mathbf{1 0 0 \%}$ & UTZ Certified, Rainforest Alliance e Fairtrade \\
Mars & $\mathbf{3 6 \%}$ & $\mathbf{1 0 0 \%}$ & Fairtrade \\
Meiji & - & - & Rainforest Alliance \\
Mondelez & $\mathbf{1 2} \%$ & - & Fairtrade \\
Nestlé & $\mathbf{9 1 , 8}$ mil ton. & - & Nescafé Cocoa Plan \\
\hline
\end{tabular}

Fonte: Elaborado pelos autores a partir de dados da pesquisa

Quanto às certificações utilizadas, Ferrero e Hershey compram cacau certificado pelas três principais organizações de certificação de produtos agrícolas. Mars, Meiji e Mondelez citam apenas uma organização, cada, em seus relatórios. A Nestlé não informa utilização dessas certificações no relatório 2014, mas o web site institucional da companhia para o Reino Unido fala sobre o uso de cacau certificado Fairtrade e UTZ em alguns produtos comercializados naquele país em 2013. É possível que Mars, Meiji e Mondelez também comprem cacau com outras certificações que não foram informadas nas fontes consultadas.

Destaca-se que, no caso do cacau, as companhias optaram majoritariamente pela aquisição de amêndoas com certificação de terceira parte. Na cadeia produtiva do café, por outro lado, as multinacionais dão preferência a certificações de primeira e segunda parte (SILVA et al., 2015). A certificação de terceira parte é importante devido à maior transparência que as organizações certificadoras oferecem ao mercado. As três certificações utilizadas combinam normas ambientais, sociais e econômicas.

\section{CONSIDERAÇÕES FINAIS}

Este estudo analisou as práticas de RSC empregadas pelas seis maiores empresas de chocolate do mundo. Mais precisamente, foram feitas análises direcionadas aos produtores e suas comunidades, além das aquisições de cacau certificado realizadas pelas companhias. Os resultados mostram que as seis empresas compram cacau certificado, investem no treinamento dos produtores e desenvolvem projetos nas comunidades. A demanda por essas ações na cadeia do cacau é grande devido às condições socioeconômicas da maioria dos produtores. 
Como a produção de cacau é realizada, majoritariamente, em países pobres e com problemas de infraestrutura, baixa produtividade e condições precárias de trabalho, é necessário que as organizações realizem investimentos no intuito de reverter este quadro e criem códigos de conduta para evitar que os membros da cadeia de suprimentos adotem posturas não condizentes com os valores difundidos pela RSC.

Atualmente, com o reconhecimento de que as cadeias de suprimentos também necessitam de monitoramento, torna-se importante que as organizações se esforcem para desenvolver, orientar e controlar práticas socialmente responsáveis entre todos os atores do processo produtivo. Diante da falha de algum elo da cadeia, a empresa poderá ser responsabilizada e sofrer sanções por parte da sociedade. Neste caso, as ações de RSC contribuem para que as companhias promovam práticas que atenuem os impactos causados por suas atividades, abrangendo todos os estágios de criação de valor.

Três das companhias analisadas, Ferro, Hershey e Mars, definiram como meta para 2020 a aquisição de 100\% de cacau sustentável. A Mondelez pretende alcançar essa meta em uma data não especificada e a Nestlé possui metas de incremento contínuo dos volumes adquiridos, embora também não mencione uma data para alcançar os 100\%. Apenas a Meiji não apresentou dados sobre quantidades adquiridas e metas para o futuro.

Os projetos desenvolvidos pelas empresas para oferecer treinamento aos agricultores e as suas ações nas comunidades são importantes, pois os principais países produtores encontram-se em situações de pobreza e de baixo desenvolvimento. No entanto, pesquisas específicas sobre essas ações poderiam lançar luz sobre os reais impactos na produtividade das lavouras e no aumento do bem-estar das comunidades.

A principal limitação desse estudo é se basear apenas nos relatórios das próprias companhias analisadas e outras fontes institucionais. Embora disponibilizem muitas informações úteis, elas são limitadas e não é possível obter aprofundamento em alguns tópicos. Estudos futuros, realizados com a utilização de entrevistas e/ou questionários junto a representantes das empresas, produtores e outros envolvidos poderão complementar o quadro delineado com este trabalho. 


\section{REFERÊNCIAS}

ALIGLERI, L. M.; ALIGLERI, L. A.; CÂMARA, M. R. G. Responsabilidade Social na Cadeia Logística: uma Visão Integrada para o Incremento da Competitividade. In: II Encontro de Estudos Organizacionais, Recife, 2002.

Anais... Recife, 2002.

ASHLEY, P. A.; COUTINHO, R. B.G.; TOMEI, P. A. Responsabilidade social corporativa e cidadania empresarial: uma análise conceitual comparativa. In: XXIV Encontro da ANPAD, Florianópolis, 2000. Anais... Florianópolis, 2000 .

ASSOCIAÇÃO BRASILEIRA DE NORMAS TÉCNICAS. NBR 16001. 2017. Disponível em: <http://www.inmetro. gov.br/qualidade/responsabilidade_social/norma_nacional.asp>. Acesso em: 09 abr. 2017.

BARON, D. P. Private politics, corporate social responsibility, and integrated strategy. Journal of Economics \& Management Strategy, v. 10, n. 1, p. 7-45, 2001.

BERTONCELLO, S. L. T.; CHANG JR, J. A importância da responsabilidade social corporativa como fator de diferenciação. FACOM-Revista da Faculdade de comunicação da FAAP, n. 17, p. 70-76, 2007.

CARROLL, A. B. A three-dimensional conceptual model of corporate performance. Academy of management review, v. 4, n. 4, p. 497-505, 1979.

CARROLL, A. B. Corporate social responsibility evolution of a definitional construct. Business \& society, v. 38, n. 3, p. 268-295, 1999.

CARROLL, A. B. Corporate social responsibility: The centerpiece of competing and complementary frameworks. Organizational Dynamics, v. 44, n. 2, p. 87-96, 2015.

CARROLL, A. B. The pyramid of corporate social responsibility: Toward the moral management of organizational stakeholders. Business horizons, v. 34, n. 4, p. 39-48, 1991.

COMISSÃO DAS COMUNIDADES EUROPEIAS. Livro Verde: Promover um quadro europeu para a responsabilidade social das empresas. 2001. Disponível em: <http://www.europarl.europa.eu/meetdocs/committees/ empl/20020416/doc05a_pt.pdf>. Acesso em: 10 abr. 2017.

CUSTODIO, A. L. M; MOYA, R. Indicadores Ethos de Responsabilidade Social Empresarial. São Paulo: Instituto Ethos, 2013. 79 p. 
DAHLSRUD, A. How corporate social responsibility is defined: an analysis of 37 definitions. Corporate social responsibility and environmental management, v. 15, n. 1, p. 1-13, 2008.

DIETZ, T.; AUFFENBERG, J. The Efficacy of Private Voluntary Certification Schemes: A Governance Costs Approach. Zentra Working Papers in Transnational Studies, n. 39, 2014.

DONADELLI, F. L. M. A Importância da Governança Privada para a Elevação de Padrões de Proteção Ambiental: um estudo de caso. 2011. 62 f. Dissertação (Mestrado em Relações Internacionais) - Universidade de São Paulo. Instituto de Relações Internacionais. São Paulo, SP, 2011.

FAIR TRADE LABELLING ORGANIZATIONS. Aims of Fairtrade Standards. 2017. Disponível em: <https:// www.fairtrade.net/standards/aims-of-fairtrade-standards.html>. Acesso em: 10 abr. 2017.

FAOSTAT. Production. Disponível em <http://faostat3.fao.org/browse/Q//E>. Acesso em: 08 abr. 2017.

FERRERO. Sharing Values to Create Value: Corporate Social Responsibility Report 2014. 2015. Disponível em: <http://www.static.ferrero.com/globalcms/documenti/2163.pdf>. Acesso em: 08 abr. 2017.

GARRIGA, E.; MELÉ, D. Corporate social responsibility theories: Mapping the territory. Journal of Business Ethics, v. 53, n. 1-2, p. 51-71, 2004.

GIL, A. C. Como elaborar projetos de pesquisa. 4. ed. São Paulo: Atlas, 2002.

GIL, A. C. Métodos e técnicas de pesquisa social. 5. ed. São Paulo: Atlas, 2007.

INTERNATIONAL COCOA ORGANIZATION. Sustainable Cocoa Economy: a comprehensive and participatory approach. 2007. Disponível em: <http://www.icco.org/about-us/international-cocoa-agreements/cat_view/ 30-related-documents/32-consultative-board-on-the-world-cocoa-economy.html>. Acesso em: 08 abr. 2017.

KPMG. Cocoa Certification: Study on the costs, advantages and disadvantages of cocoa certification commissioned by The International Cocoa Organization (ICCO). 2012. Disponível em: <http://www.icco.org/ about-us/international-cocoa-agreements/cat_view/30-related-documents/37-fair-trade-organic-cocoa. html>. Acesso em: 08 abr. 2017.

KREITLON, M. P. A ética nas relações entre empresas e sociedade: fundamentos teóricos da responsabilidade social empresarial. In: XXVIII Encontro Anual da Anpad, Curitiba, 2004. Anais... Curitiba, 2004. 
LEE, M.D. P. A review of the theories of corporate social responsibility: Its evolutionary path and the road ahead. International journal of management reviews, v. 10, n. 1, p. 53-73, 2008.

MADRAKHIMOVA, F. S. Evolution of the concept and definition of corporate social responsibility. Global Conference on Business \& Finance Proceedings, v. 08, n. 2, p. 113-118, 2013.

MALONI, M. J.; BROWN, M. E. Corporate social responsibility in the supply chain: an application in the food industry. Journal of business ethics, v. 68, n. 1, p. 35-52, 2006.

MARS. Mars Chocolate Gender Action Plan in Vision for Change Program (V4C) Côte d'Ivoire. 2014. Disponível em: <http://cocoasustainability.com/wp-content/uploads/2014/06/Mars-Action-Plan-to-Address-Gender-Issues-within-V4C-FINAL-06-27-14-.pdf>. Acesso em: 04 mar. 2016.

MARS. Principles in Action: Summary 2014. 2015. Disponível em: <http://www.mars.com/global/assets/ doc/pia_exec_2014/Mars_Principles_in_Action_Summary_2014_EN.pdf>. Acesso em: 04 mar. 2016.

MEIJI HOLDINGS. 2014 Annual Report. 2015. Disponível em: <http://www.meiji.com/global/investors/results-and-presentations/annual-reports/pdf/2014/annual-reports_2014_en_all_print.pdfs. Acesso em: 04 mar. 2016.

MEIJI HOLDINGS. Featured: Sustainable Cocoa Farming. 2016. Disponível em: <http://www.meiji.com/global/sustainability/sustainable-cocoa-farming/>. Acesso em: 04 mar. 2016.

MONDELEZ INTERNATIONAL. The Call for Well-Being: 2014 Progress Report. 2015. Disponível em: <http:// www.mondelezinternational.com/ /media/MondelezCorporate/uploads/downloads/CFWB2014ProgressReport.pdf>. Acesso em: 04 mar. 2016.

NEERGAARD, P. ; PEDERSEN, E. R. Expanding the concept of quality management to global supply chains.

Asian Journal on Quality, v. 6, n. 1, p. 98-108, 2005.

NESTLÉ. Child Labour. 2016a. Disponível em: <http://www.nestle.com/csv/human-rights-compliance/child-labour>. Acesso em: 04 mar. 2016.

NESTLÉ. Nestlé Cocoa Plan. 2016b. Disponível em: <http://www.nestle.com/csv/rural-development-responsible-sourcing/nestle-cocoa-plan>. Acesso em: 04 mar. 2016.

NESTLÉ. Nestlé in Society: Creating Shared Value and meeting our commitments 2014. 2015. Disponível em: <https://www.nestle.com/asset-library/documents/library/documents/corporate_social_responsibility/ nestle-in-society-summary-report-2014-en.pdf>. Acesso em: 04 mar. 2016. 
NESTLÉ. The Nestlé Cocoa Plan. S.d. Disponível em: <http://www.nestle.co.uk/csv2013/socialimpact/responsiblesourcing/nestlecocoaplan>. Acesso em: 02 abr. 2016.

OLIVEIRA, M. M. Como fazer pesquisa qualitativa. Petrópolis: Vozes, 2007.

PEDERSEN, E. R.; ANDERSEN, M. Safeguarding corporate social responsibility (CSR) in global supply chains: how codes of conduct are managed in buyer supplier relationships. Journal of Public Affairs, v. 6, n. 3-4, p. 228-240, 2006.

POHL, M. Corporate Culture and CSR: How They Interrelate and Consequences for Successful Implementation. In: HENNIGFELD, J.; POHL, M.; TOLHURST, N. (Org.). The ICCA handbook on corporate social responsibility. England: John Wiley \& Sons, p. 47-59, 2006.

RAINFOREST ALLIANCE. What does Rainforest Alliance Certified ${ }^{\mathrm{TM}}$ Mean? 2016. Disponível em: <http:// www.rainforest-alliance.org/faqs/what-does-rainforest-alliance-certified-mean>. Acesso em: 10 abr. 2017.

RAYNOLDS, L. T., MURRAY, D., HELLER, A. Regulating sustainability in the coffee sector: A comparative analysis of third-party environmental and social certification initiatives. Agriculture and Human Values, v. 24, n. 2, p. 147-163, 2007.

RODRIGUES, P. C. S. Governança e regulação transnacional privada: os limites do sistema agroindustrial da soja. 2013. 134 f. Dissertação (Mestrado em Ciência Política) -Universidade de São Paulo. Faculdade de Filosofia, Letras e Ciências Humanas. Departamento de Ciência Política. São Paulo, São Paulo, 2013.

SCULLY, C. Z. 2014 Global Top 100: Candy Industry's exclusive list of the Top 100 confectionery companies in the world! 2014. Disponivel em: <http://www.candyindustry.com/articles/86039-global-top-100-candy-industrys-exclusive-list-of-the-top-100-confectionery-companies-in-the-world?page=5>. Acesso em $10 \mathrm{fev}$. 2016.

SEURING, S.; SARKIS, J.; MÜLLER, M.; RAO, P. Sustainability and supply chain management: an introduction to the special issue. Journal of Cleaner Production, v. 16, n. 15, p. 1545-1551, out. 2008.

SILVA, E. C. et al. Governança privada e sustentabilidade na indústria do café. In: Encontro Internacional sobre Gestão Empresarial e Meio Ambiente, XVII, 2015, São Paulo. Anais... São Paulo, 2015.

THE HERSHEY COMPANY. 2014 Corporate Social Responsibility Report. 2015. Disponível em: <http:// 
www.thehersheycompany.com/social-responsibility/shared-goodness/pdfs/Hershey2014CSRReport.pdf>. Acesso em: 04 mar. 2016.

TULANE UNIVERSITY. Final Report 2013/2014: Survey Research on Child Labor in West African Cocoa Growing Areas. Disponível em: <http://makechocolatefair.org/sites/makechocolatefair.org/files/newsimages/ tulane_university_-_survey_research_on_child_labor_in_the_cocoa_sector_-_30_july_2015.pdf $>$. Acesso em: 19 fev. 2016.

UTZ CERTIFIED. Who we are. 2017. Disponivel em: <https://utz.org/who-we-are/>. Acesso em: 10 abr. 2017.

WINDSOR, D. The future of corporate social responsibility. The international journal of organizational analysis, v. 9, n. 3, p. 225-256, 2001.

WORLD BUSINESS COUNCIL FOR SUSTAINABLE DEVELOPMENT. Corporate Social Responsibility: meeting changing expectations. WBCSD Publications, 1999. Disponível em: <http://old.wbcsd.org/pages/edocument/edocumentdetails.aspx?id=82\&nosearchcontextkey=true>. Acesso em: 10 abr. 2017. 